\title{
NEW RESEARCH LABORATORIES FOR THE PAINTS DIVISION OF IMPERIAL CHEMICAL INDUSTRIES LTD.
}

\begin{abstract}
T is no exaggeration to say that, within the past twenty-five to thirty years, a revolution has taken place in the paint industry which has changed paintmaking from an art into a science. As a result, the simple linseed oil/natural resin paints which had been in use for centuries have been displaced almost entirely by a wide range of synthetic coatings, each of which is specially formulated for the conditions under which it will be applied, and for the performance it will have to give, whether this is on a house, a high-speed aircraft, a motor-car, a household appliance or on one of the many other surfaces to which paints and lacquers are now applied.

This rapid development of modern paint coatings is the result of the interplay between the increasingly stringent requirements of the users and the research and development work earried out within the industry to anticipate these needs. The applied research necessary to produce the required products has in turn been nourished and stimulated by the fundamental research on polymers carried out within the industry and at universities and research institutions, and by the increasing range of synthetic raw materials that have become available from the chemical industry.
\end{abstract}

The Paints Division of Imperial Chemical Industries Ltd., which was one of the first paint companies in the United Kingdom to establish a research depart. ment some thirty years ago, has always placed considerable emphasis on research directed towards improving its existing products and to the production of new ones. To improve the accommodation for its Research Department, a five-storey block of laboratories has been erected recently on the Division's headquarters site at. Slough, Bucks.

The new building, which is $48 \mathrm{ft}$. wide $\times 160 \mathrm{ft}$. long, provides about $30,000 \mathrm{sq}$. $\mathrm{ft}$. of working space for laboratories, offices and the library of the Division.

It is constructed of in situ concrete faced with Leicester golden brown and Vandyke brown bricks, ornamented with blue mosaic column facings and artificial stone copings, and is planned on a 5-ft. longitudinal module. On all floors, the main corridor has been offset from the centre line, giving 22 -ft. wide rooms on the north side and $15-\mathrm{ft}$. wide rooms on the south side. On the lower floors, where it is unlikely that the function or size of rooms will need to be altered, the walls are generally of solid construction; but on the higher floors, where changes are more likely to occur, 'Holoplast' partitioning has been used.

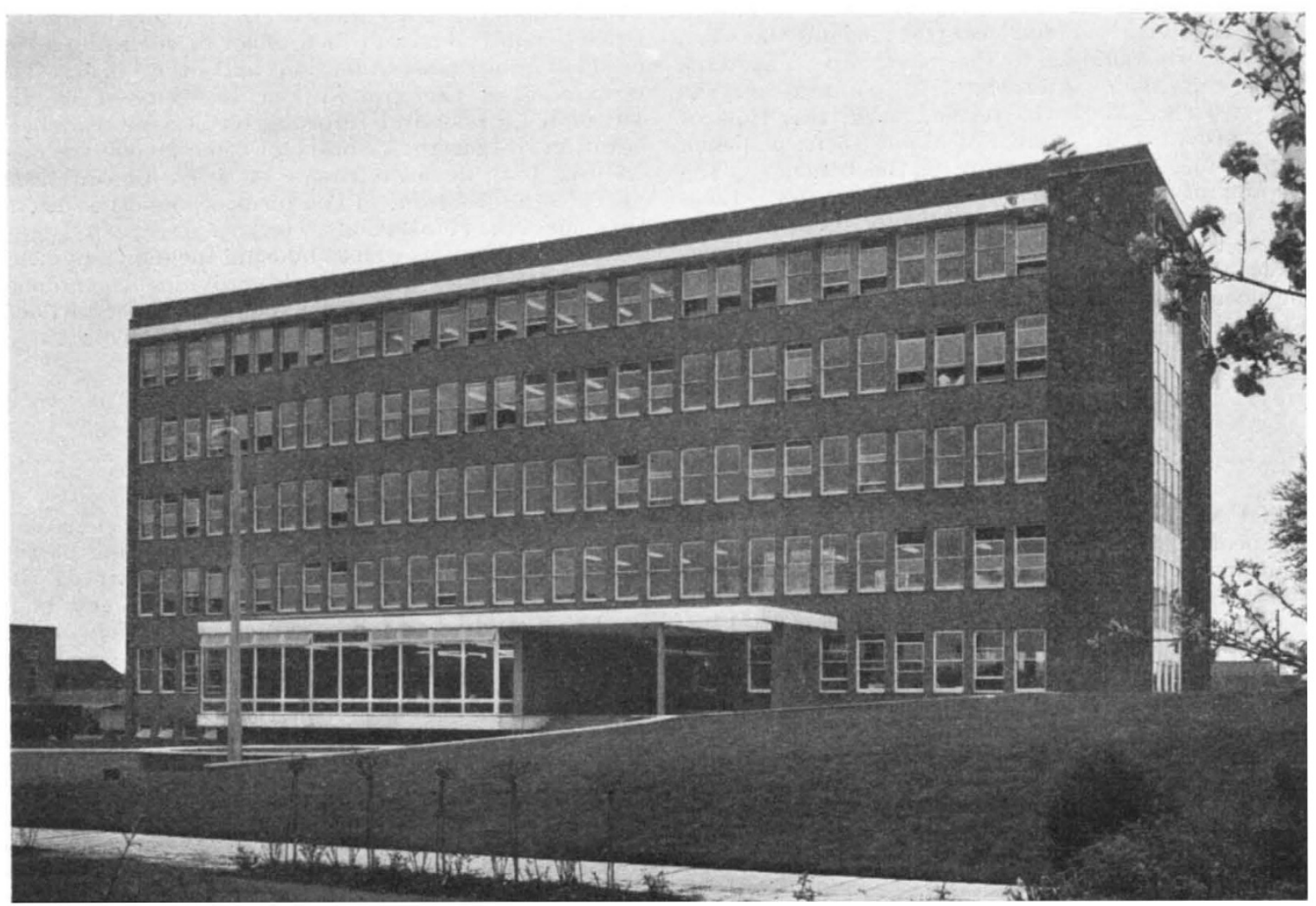

Fig. 1. North and west sides of I.C.I. Paints Division's new research laboratories at Slough, Bucks., showing the entrance and library reading room on the left 
Floors generally are covered with large grey linoleum tiles finished with a polyurethane lacquer. The 5-ft. spacing of the columns on the outside walls has allowed for the provision of large sash windows, and the false ceilings, above which are carried the horizontal service distributions for the floor above, are rebated on the window side to increase the window height to the maximum.

Space heating is carried out by means of hot-water convectors built into the walls below the window sills. Window ventilation is relied on for offices, but in the laboratories, the fume-cupboard system provides the main ventilation. The fume-cupboard fans are run continuously throughout the day, warmed replacement air, cleaned by electrostatic precipitation, being supplied to all laboratories through a system of trunking concealed in the corridor ceiling.

To enable the extract ducts from fume cupboards on the lower floors to be carried up to the roof without interfering with the design of laboratories on the upper floors, the majority of the fume cupboards are recessed into a 4 -ft. wide longitudinal strip which has been provided on all floors between the corridor and the laboratories on the wide side. Vertical ducts located in this strip carry the extract trunking from the different groups of fume cupboards up to the exhaust fans on the roof. Similar ducts carry the main risers for the piped and electrical services and the laboratory drainage. Access to all these ducts and to the backs of fume cupboards is provided from doors in the corridor, thereby minimizing interference with work in the laboratories when maintenance is necessary.

In general, 5-ft. wide double-sided island benches at right-angles to the windows have been adopted as the standard with a 5 -ft. walk-way between, giving a 10-ft. centre-to-centre spacing between benches, corresponding to the 10 -ft. tap-off systems on the ring mains and the 5 -ft. columns on the window walls. With the present staff, this type of layout provides an average of about $15 \mathrm{ft}$. of bench per person. A special feature of the benches is the grouping of the service outlets into towers. Flectrical sockets are mounted vertically on the fronts of these towers, with the water-control valves immediately above them, the corresponding water outlets being located at the side of the towers over a central lead-lined trough drain. The outlets for gas services (town gas, compressed air or nitrogen) are at the base of each tower, with extended control spindles to handles mounted on the fascia of the bench. The tops of the towers are recessed to carry the ends of over-bench shelves, beneath and on each side of which are mounted lengths of 'Unistrut' channel. On these slide specially designed clamps for the erection of bench scaffolding, thus eliminating the need to use retort stands for the support of apparatus. Similar 'Unistrut' channels have been provided on the walls in many laboratories for the erection of tall apparatus, and in these locations wall service outlets have also been provided.

Bench tops are either of teak, stainless steel or 'Formica' according to the particular type of work being carried out on them. The underbench furniture is of painted softwood and consists of 3-ft. 4-in. long interchangeable cupboard and drawer units.

The laboratories on the top floor of the building are devoted to organic chemical work directed towards the discovery of new polymers which may be of value as surface coatings, while those on the second and third floors are concerned with the further development of these polymers into paints and with their evaluation in comparison with standard products. The second floor also provides accommodation for the research management, administration, a central typing service and a conference room. The first floor is almost entirely occupied by the Physical Chemistry and Analytical Sections, both of which make extensive use of physical techniques such as infra-red and ultra-violet spectroscopy, polarography and chromatography, etc. The Physics Section, which is housed on the ground-floor, is concerned with problems involved in the dispersion and physical behaviour of pigments and with the physical characteristics of paint films and their effect on such properties as gloss, hardness, adhesion and durability. The remainder of the ground-floor is occupied by the Division Library and Information Service, which, in addition to housing a library of some 20,000 volumes dealing with a wide range of scientific interests, provides information in the form of bulletins, literature surveys, translations, etc.

The basement, as well as housing the main engineering services for the building, also provides accommodation for two air-conditioned rooms used for physical tests on paint films.
J. W. Dorling

\section{NORTH BORNEO EXPEDITION 1961}

$\mathrm{M}^{2}$ OUNT KINABALU $(13,455 \mathrm{ft}$.) is the highest peak between the Himalayas and the Snow Mountains of New Guinea, and, though not a snowmountain itself, it has an alpine flora relating these two parts of the world. It was first climbed in 1851 by Sir Hugh Low and has since attracted many botanists, zoologists and geologists. It is now known to have one of the richest floras of any mountain, but a great part of it remains to be explored.

To further the biological exploration of North Borneo, which will also assist the Government of North Borneo in its plans for the establishment of a national park on this famous mountain, the Royal Society set up in 1960 a committee under the chairmanship of Sir Joseph Hutchinson. This year, in co-operation with the Government of North Borneo, the Society has sent out a reconnaissance expedition under the leadership of Mr. E. J. H. Corner to investigate the practically unexplored eastern side of the mountain, where the forest extends down to the lowlands. In particular, the vegetation and soils are being studied as indicators of land which should be conserved within the boundaries of the national park. It is well known that in these precipitous regions of high rainfall, the clearing of luxuriant primary forest may lead to irreparable impoverish. ment of the soil with erosion and consequent silting and flooding of the rivers.

As soil-scientist, Mr. G. P. Askew (Wye College, University of London) is accompanying the expedition to work in conjunction with the Soils Division of the Department of Agriculture in North Borneo. Mr. Adam Stainton, who has taken part in the botanical exploration of Nepal, organized through the British 